\title{
Aula de português: ensino de uma língua estrangeira para brasileiros*
}

\section{Portuguese class: teaching a foreign language for Brazilians}

\author{
Gilberto de Castro**
}

A melhor maneira que a gente tem de fazer possível amanhã alguma coisa que não é possivel fazer hoje é fazer hoje aquilo que hoje pode ser feito. Mas, se eu não fizer hoje o que hoje pode ser feito e tentar fazer hoje o que hoje não pode serfeito, dificilmente eu farei amanhã o que hoje também não pude fazer.

Paulo Freire

\begin{abstract}
RESUMO
A partir de três histórias de aula de português, cujos desencontros de interpretação exemplificam bem a distância grande que muitas vezes existe entre o que se ensina e o que se aprende, o texto propõe uma reflexão sobre o problema do confronto cultural que ocorre diariamente entre a linguagem da escola (do professor e dos textos) e a fala dos alunos, chamando a atenção para o aspecto educacionalmente danoso de ignorarmos a imensa diversidade cultural existente sob o teto falso da crença de que por sermos brasileiros falamos todos uma mesma língua.

Palavras-chave: ensino de língua portuguesa, lingüística, língua portuguesa, leitura.
\end{abstract}

* Este artigo é uma versão ampliada do texto apresentado no XV Seminário do CELLIP, em 2001. Alguns aspectos da linguagem informal foram mantidos propositalmente.

** Doutor em Lingüística pela USP. Professor de Metodologia e Prática de Ensino de Língua Portuguesa do DTPEN/UFPR. castrog@uol.com.br 


\begin{abstract}
With three histories of Portuguese language classes, whose misunderstandings exemplify the wide distance that not rarely exists between what is tough and what is learnt, this text propose a reflection about the problem of daily cultural confrontation that occurs between school language (from teacher and texts) and student speech. This text pays special attention for the specially damaging aspect of our ignorance to the immense cultural diversity, under the false belief that because we are Brazilians we speak the same language.
\end{abstract}

Key-words: Portuguese language teaching, linguistic, Portuguese language, reading.

Vou contar três histórias de aula de português. A primeira é uma história pessoal, a segunda é de uma ex-aluna minha da graduação e a terceira é de Graciliano Ramos, retirada do seu livro Infância.

Primeiro a história pessoal.

De todos os assuntos e temas de língua portuguesa que estudei na escola, sem que consiga precisar o motivo, há um que sempre me vem à memória, principalmente quando falo em metodologia de ensino para meus alunos. Refiro-me a um conjunto de aulas sobre sintaxe que tive no início do antigo ginásio.

O professor era uma figura pequena, simpática, embora de poucos sorrisos. Extremamente ágil, ele corria de um lado pro outro, ostentando seu paletó cinza brilhante, preenchendo os espaços do quadro com frases tiradas da memória e de um livrinho de capa verde, sobre o tema do objeto direto.

Imagino que não só eu, mas todos os meus colegas, cada um a seu modo - e calados -, tentávamos em vão entender o que significava aquele objeto. De minha parte, sem entender quase nada do que o professor falava, fiquei me perguntando que objeto seria aquele. Sem encontrar no quadro nenhum objeto definido, pensei que aquele tal de objeto deveria ser uma coisa qualquer; sim, um objeto qualquer. Comecei a acertar, afinal o que era um objeto eu sabia muito bem. Muita coisa podia ser um objeto. Uma bola, por exemplo? Pensei primeiro numa bola, o objeto de que mais gostava e que perseguia todos os dias, feliz e incansável, antes e depois das aulas. Mas achei que o objeto bola não era bom - algo me dizia que não era correto misturar escola com diversão. E pela repressão que sofríamos por causa das eventuais peladinhas do recreio, sabia que o 
professor também não ia gostar do meu objeto. Bem, se não podia bola, por que não uma cadeira? Sim, cadeira era um objeto legal. A gente sentava nela pra comer, pra rezar e, principalmente, pra assistir às aulas na escola. Me satisfiz com a idéia da cadeira e passei ao passo seguinte, esforçando-me agora para compreender a expressão objeto direto inteira. Mas aí logo empaquei novamente, pois como resolver o problema de um objeto, assim, direto? Sacudi a minha imaginação juvenil mais uma vez e, auxiliado pela física futebolística que conhecia muito bem, livrei-me da cadeira, como um goleiro, lançando-a pelo ar diretamente, em direção desconhecida. Não havia dúvidas, um objeto direto só podia ser uma coisa assim, como uma bola, jogada pra frente.

Esse nível de compreensão, embora não muito coerente, já estava me satisfazendo. Com a cabeça longe e sentado na minha cadeira voadora, distraía-me, copiando mecanicamente os exemplos que o professor escrevia no quadro, tentando, às vezes, identificar a minha teoria com a prática rabiscada por ele.

Mas aí apareceu um novo problema teórico pra resolver ou, quem sabe, uma variação do mesmo problema. O pequenino professor disse que além do objeto direto existia o irmão dele, meio parecido, mas também bem diferente. E a turma silenciou, aguardando o outro membro da família aparecer, esperando que ele fosse mais simples e comportado do que o primeiro. Aí, o professor virou pro quadro negro, sacudiu-se um pouco e, voltando pra gente, com um sorrisinho contente na cara, apresentou, orgulhoso, no meio de uma frase, o objeto indireto! Silêncio na turma: os irmãos eram realmente muito parecidos, mas igualmente esquisitos. Não havia dúvidas que eram mesmo membros de uma mesma família; afinal os dois eram objetos! Mas se eram, como o professor disse, também diferentes, onde estava a diferença? Pra resolver meu problema, vi que recorrer ao mesmo instrumental teórico utilizado anteriormente poderia ser produtivo. Voltei, assim, à idéia da cadeiral objeto. Se o objeto direto podia ser algo lançado diretamente, pra frente, imaginei o contrário pro objeto indireto. Feliz e aliviado, lancei, então, a cadeira voadora de ré ao infinito e pude perceber que de fato o objeto direto e o indireto eram realmente diferentes, mesmo sendo irmãos, como havia dito o professor. Resolvido o problema teórico, voltei a me concentrar na cópia dos muitos exemplos que o meu mestre continuava a registrar no quadro-negro, tentando encaixar em alguns deles a minha cadeira. Mas as tentativas foram vãs, não havia lugar pro meu objeto naquelas frases! 
A segunda história é mais ou menos assim:

Certa vez, numa de minhas aulas de Prática de Ensino, uma aluna, que já era professora há algum tempo, contou que havia ficado muito surpresa e decepcionada com um conjunto de aulas que vinha ministrando, pra várias turmas, ao longo de umas duas semanas. As turmas eram, se bem me recordo, de sétima série de uma escola particular de Curitiba. E o tema girava em torno de algumas reflexões sobre o português e suas variações.

Ela relatou que já no início do trabalho, lá pelas primeiras aulas, num determinado momento, fez uso da expressão língua materna. Depois de ter inserido a nova terminologia, assim, de forma natural, achando-a simples e clara, foi repetindo a mesma expressão várias vezes ao longo de toda a abordagem do conteúdo. Lá pelas tantas, num momento já avançado das exposições, veio, de um daqueles alunos corajosos, a questão fatal: - Professora, o que que é essa língua materna que a senhora tá falando tanto? Ora o que era a língua materna, então ela por acaso já não tinha explicado? Língua materna era o português; sim, esse português que todos nós falamos! A língua do país, ora! O aluno continuou com uma cara de interrogação. E o pior é que a interrogação agora não era mais só do indagador; um vivo interesse pela questão tomou conta da turma. Mas como podia acontecer uma coisa dessas? Pensava minha aluna. Aquela expressão era tão simples! Não era?

Não conformada com a dúvida dos alunos, passou ela a ter uma dúvida cruel. O que, afinal, aqueles diabinhos tinham entendido por língua materna? Espreme daqui, espreme dali, e um outro corajoso, já nos limites da tortura, entregou o serviço. Professora, mas língua materna não é a língua da mãe da gente? Boquiaberta, minha aluna, teve que agüentar, estupefata, a evidência de que essa terrível e inesperada interpretação, para seu espanto e desgosto, não era uma interpretação isolada. Muitos, além do segundo corajoso, achavam a mesma coisa. A língua materna era mesmo a língua da mãe da gente - aquela da boca - que elas, as mães, usam pra falar. A história termina aqui, mas as aulas sobre o assunto tiveram que recomeçar ali mesmo.

A terceira história retirei, como disse, de Infância, livro de memórias de Graciliano Ramos.

Nesse texto belíssimo, entre tantas coisas curiosas, Graciliano vai nos contar dos terríveis percalços que passou para se inserir no mundo das letras, num sertão sem muita sensibilidade e quase sem escola. No capítulo 
leitura, ele relata que um dia, no meio de vários objetos que lhe mostrava o pai, havia alguns cadernos com alguns escritos. Como ele se interessou pelos cadernos, folhando e percorrendo algumas de suas páginas, o pai interpretou aquilo como um desejo irrefreável do filho em ser alfabetizado. Passou então a um discurso pedagógico, mostrando as maravilhas que o universo da escrita guardava, a fim de salvar, ele mesmo, o filho das trevas do analfabetismo. Na fala do próprio Graciliano, o pai "Afirmou que as pessoas familiarizadas com elas [as letras, palavras] dispunham de armas terríveis. Isto me pareceu absurdo: os traços insignificantes não tinham feição perigosa de armas. Ouvi os louvores incrédulo.” (p. 104)

E Graciliano continua:

Certamente meu pai usara um horrível embuste naquela manhã, inculcandome a excelência do papel impresso. Eu não lia direito, mas, arfando penosamente, conseguia mastigar os conceitos sisudos: "A preguiça é a chave da pobreza. - Quem não ouve conselho raras vezes acerta. - Fala pouco e bem: ter-te-ão por alguém."

Esse Terteão pra mim era um homem, e não pude saber que fazia ele na página final da carta. As outras folhas se desprendiam, restavam-me as linhas em negrita, resumo da ciência anunciada por meu pai. (p. 109)

Mas a dúvida ficou povoando a cabecinha de nosso escritor que, o mais rápido que pode, foi se socorrer com Mocinha, a irmã mais velha.

- Mocinha, quem é o Terteão?

Mocinha estranhou a pergunta. Não havia pensado que Terteão fosse um homem. Talvez fosse. "Fala pouco e bem: ter-te-ão por alguém." Mocinha, que quer dizer isso?

Mocinha confessou honestamente que não conhecia Terteão. E eu fiquei triste, remoendo a promessa de meu pai, aguardando novas decepções. (p. 109)

Eu poderia contar mais um monte de histórias como essas, mas creio que as que estão aqui já servem bem para exemplificar onde quero chegar. Mesmo assim, gostaria de acrescentar mais um exemplo que encontrei no 
livro sobre estrangeirismos (Estrangeirismos - guerras em torno da língua), lançado no final de 2001, que tem tudo a ver com que estou contando. O exemplo é muito bom e está no texto Estrangeirismos - desejos e ameaças, de Pedro M. Garcez e Ana Maria Zilles. Contra as idéias ingênuas e falaciosas dos que crêem numa língua única, pura e de todos, os autores vão contra-argumentar, dizendo:

Conforme esse raciocínio, o estrangeirismo ameaça a unidade nacional porque emperra a compreensão de quem não conhece a língua estrangeira. Isso seria equivalente a afirmar que um enunciado como "Eu baixei um programa novo de computador" seria "plenamente compreensível por todos os brasileiros de qualquer rincão, independentemente do nível de instrução e das peculiaridades da fala e escrita" (...), porque não contém estrangeirismos, mas isso não passaria com o enunciado " $E u$ fiz $o$ download de um software novo", que seria incompreensível a qualquer brasileiro que não conhecesse o inglês, em função dos estrangeirismos. Vale perguntar se seria de fato "plenamente compreensível por todos os brasileiros de qualquer rincão, independentemente do nível de instrução e das peculiaridades regionais da fala e escrita" o texto da justificativa do projetos de lei, por exemplo, quando faz a seguinte afirmação, sem estrangeirismos: "Não se trata de xenofobia ou intolerância agir em prol da língua pátria." (p. 29-30)

Alguém pode pensar que as três histórias contadas aqui e o exemplo retirado do livro falam de vocabulário - e até é verdade que também falam -, mas eu gostaria de pensar que todos esses exemplos contam algo bem mais importante e mais grave do que isso. Porque na verdade nós - todos nós - não sabemos ou aprendemos palavras, o que temos sim são experiências acumuladas que não se descolam das palavras, que se traduzem nelas e por elas. As palavras das línguas, assim como as regras que as estruturam, não andam sozinhas e avulsas sobre as nossas cabeças como se compusessem uma gramática ou um dicionário. Para entendê-las, precisamos compreender a sua finalidade, entender e participar do mundo de onde elas vêm, as experiências sociais que as geraram e que as contemplam.

E as experiências/regras/palavras diversas estão, tal como os seus donos, espalhadas e distribuídas entre crianças, moços e velhos, meninos e 
meninas, homens e mulheres, pretos e brancos, pobres e ricos, sulistas e nordestinos, favelados e bem nascidos de uma mesma cidade, profissionais das mais diversas categorias, marginais etc. Nossas experiências com a língua vão muito mais longe do que aquelas diferenças sociogramaticais (os dialetos) já tão bem demonstradas pela sociolingüística. Cada grupo social, cada indivíduo isoladamente, ocupa, de forma inevitável, uma posição no mundo, a qual é sempre singular. E é desse lugar, desse mirante, que nós observamos, compreendemos e criamos o mundo. Mas esse mirante está longe de qualquer pureza, porque está erguido sobre as estruturas das diferenças sociovalorativas, dos padrões de gosto, das possibilidades de consumo, das características socioregionais, das tradições histórico-familiares com seus temas respectivos, dos vários valores ético-religiosos, da masculinidade ou da feminilidade.

Alguém pode perguntar aqui, e com toda razão, onde está a novidade de tudo isso, uma vez que parece que esse papo sobre diferenças culturais, idiossincrasias históricas, sociais e econômicas, multiplicidade de variantes de uma língua nacional, já está pra lá de manjado no mundo acadêmico e no discurso oficial da escola, depois de tudo que o último século já produziu através dos estudos humanísticos e lingüísticos. Desse ponto de vista, de um ponto de vista acadêmico/teórico/abstrato, certamente parece mesmo que não há mais muito o que falar ou questionar a respeito. Às vezes, temos mesmo a impressão de que já sabemos tudo de que precisamos!

Apesar disso, não sei se podemos dizer com segurança que esse legado teórico/abstrato, principalmente em termos de ensino de línguas - e da materna em particular -, encontrou o seu eco empírico de fato. Porque, à semelhança da mídia, que constrói e alimenta a idéia de que existe uma mulher do novo milênio, que existiu um homem dos anos 90 , que existirá a criança do próximo século, o jovem moderno, o profissional eficiente, parece que em termos educacionais cremos também mais em classificações e abstrações do que nos eventos educacionais/culturais que acontecem de fato nas escolas, através de realizações pedagógicas concretas (as aulas). Assim como as classificações e abstrações da mídia, tão capciosamente utilizadas para unificar padrões de consumo, de gosto e comportamento, num universo de possibilidades não unificáveis pelas inúmeras razões sociais que conhecemos, tendemos à aceitação, quase inconsciente, do rigor imposto pela seriação, já sistematizada em conteúdos, antes de chegarmos à escola - como aluno ou professor. Parece haver um descompasso grande entre o que já conhecemos teoricamente através das descobertas humanísticas do último século e o exercício prático-cultural que somos capazes de realizar. No nosso exercício 
relacional de fato e diário, dentro e fora da escola, nossos olhos ainda se encontram nublados para a percepção de importantes diferenças culturais diferenças que poderíamos dizer ironicamente são só aparentes, afinal, somos todos nascidos na mesma terra.

O resultado prático disso tudo é que continuamos a ignorar as dificuldades culturais impostas por tudo aquilo que está falado e escrito no português padrão, que, mesmo muito negado e criticado por muitos de nós, continua exercendo a representação de valor máximo de nossa cultura em termos de língua. E isso é extremamente complicado, porque tanto esse padrão único e universal, do qual mentalmente não conseguimos nos livrar, quanto os brasileiros teoricamente uniformes, para quem ele se dirige, não passam de ficção, de conceitos puramente abstratos. É claro que as abstrações são importantes e necessárias na escola e no trabalho acadêmico (difícil dar uma aula ou fazer um artigo acadêmico sem recortes, sem pensar por partes), mas elas não deveriam ser mais do que atalhos para encontrarmos as múltiplas refrações do nosso objeto científico e escolar. Infelizmente, os dados da realidade indicam que ainda estamos longe dessa consciência e de uma nova prática, principalmente quando nos deparamos com os resultados sofríveis em rendimento lingüístico de nossos estudantes, sejam de escolas públicas ou privadas, quando avaliados nacional ou internacionalmente em termos de prática de texto e de capacidade de leitura. Para dar um exemplo, lembro de uma das bancas de correção de redação do vestibular aqui da UFPR, de que participei. No meio das cinco questões propostas, havia uma questão de transformação de perguntas de uma entrevista em um pequeno texto informativo. O detalhe importante da questão - detalhe aparentemente simples mas não menos trágico - era que o enunciado da proposta de texto falava em transposição de discurso direto para discurso indireto. Embora aos tropeços, pela forma terrivelmente descolada de contexto com que esse tema é ensinado na escola, a maioria da garotada até deu conta da tarefa solicitada. Apesar disso, pelo excessivo número de provas em que essa questão foi deixada em branco - o maior índice em branco da prova de redação como um todo - e pelas tentativas desajeitadas de um ou outro estudante para tentar descobrir na hora o que vinha a ser esse tal de discurso direto e indireto, preenchendo linhas absurdamente desconexas com o que havia sido pedido, ficou patente que grande parte dos estudantes desconhecia a nomenclatura utilizada na elaboração da questão. Ficou claro que quem não fez a questão não sabia o que significava discurso direto e discurso indireto!

Antes que me acusem de estar jogando responsabilidade demais nos braços da educação, particularmente da educação lingüística, e de ignorar as 
imensas causas externas que prejudicam a educação como um todo, gostaria de me defender, dizendo que também sobre aquilo que é externo ao nosso objeto de ensino, escamoteamos nosso olhar para a realidade das diferenças que nos separam, e para as possibilidades reais de sucesso escolar ou não, da massa que hoje freqüenta a escola. Ou seja, não é só o padrão lingüístico que nos aprisiona e exige, de forma desigual, um determinado nivelamento. No fundo, também queremos - e me parece verdadeiro e justificável querê-lo também - nivelar os anos de estudo, a possibilidade de todos chegarem - se com sucesso não se sabe - aos mesmos mirantes educacionais, os mais avançados possíveis. Mas também, lá no fundo, não dá pra ignorar que até aqui as forças externas à escola são as reais campeãs e têm, sistematicamente, vencido o jogo de goleada - ou por hipocrisia ou por idealismo demais, preferimos fazer de conta que a realidade não tem sido de fato assim. É só contar as estatísticas do número de evasão escolar existente no país em todas as séries. Vendo assim, não seria mais honesto - ainda que sem deixar de buscar os índices sociais/escolares mais otimistas - relativizar um pouco mais essa nossa expectativa em relação à justiça social que poderíamos fazer via educação, através da conquista de uma permanência mais duradoura dos alunos na escola? Um esforço maior de discussão para descobrirmos formas de fazer coisas a mais e melhor com os alunos enquanto ainda estão na escola não seria mais eficaz como alternativa de diminuição de algumas de nossas distâncias socioculturais?

Não estou propondo que abandonemos utopias e metas e que entreguemos a rapadura assim facinho, mas será que tornar mais nítida uma parte cruel da face de nossos problemas educacionais - o trato particular com a linguagem (com as linguagens) - não ajudaria mais ao debate e a um melhor dimensionamento de nossas mazelas e expectativas educacionais? Não tenho nenhuma resposta para a pergunta, daí a razão da dúvida, mas penso que sou movido por uma angústia inerente a quem educa: aquela de querer poder ensinar sempre mais do que se ensina. De poder desenvolver e dividir mais e melhores experiências de vida e intelectual com todos os tipos de aluno, enquanto eles puderem permanecer na escola. Quem sabe se uma concentração maior de esforço no "tempo-agora" - os momentos concretos de relação entre professores e alunos na escola -, que está habitado por uma grande diversidade de alunos, com as multiplicidades de experiências familiares e sociais que carregam, não seja uma maneira mais adequada - e possível - de amenizar e talvez diminuir distâncias sociais. Talvez sim, se conseguirmos aprender formas melhores de dividir um pouco mais o capital cultural e lingüístico - expresso principalmente pela linguagem escrita - que, queiramos ou não, 
faz falta a quem não o possui. E o "tempo-futuro" - os anos que os alunos eventualmente conseguiriam/deveriam permanecer na escola -, que transcende o nosso objeto, obviamente também deverá continuar sendo uma meta a ser buscada, desde que esse tempo não nos desvie da enorme responsabilidade metodológica imposta já há muito no Brasil pelos tristes resultados que a educação lingüística brasileira tem colhido. Mas para isso, talvez seja preciso tocar naquilo que nos desagrada - que evidentemente nos põe limitados na ação - e pensar que, no meio da política externa ao nosso objeto específico de ensino - entre tantas faltas materiais -, está uma população imensa de brasileiros diferentes de nós que, às vezes, de comum conosco, têm apenas o gosto pelo futebol.

Enfim, ver aquilo que antecede o nosso debate de dentro da sala de aula, encarar as medidas exatas disso tudo, talvez nos ajude a ajustar melhor o tamanho de nossa teoria e método, suas fraquezas e virtudes. Porque vivemos não só a ilusão de que há uma igualdade linguiística num país desse tamanho como também que é possível e forçoso insistir na idéia de que precisamos desenvolver padrões bacanas - na maioria inexeqüíveis - de comportamento social. Um bom exemplo disso é o que o senso comum da mídia e da rua - e nós mesmos repetimos dentro da escola o tempo todo em relação à leitura. Mesmo considerando que a grande maioria das escolas públicas brasileiras está longe do ideal de oferta de livros para a leitura (acho que políticas públicas de circunstância não podem ser levadas a sério, embora surtam um ou outro efeito), que o pequeno - nulo mesmo, muitas vezes - poder aquisitivo dos pais e dos alunos é obstáculo sério ao consumo de jornais, revistas e livros e que as políticas governamentais são quase sempre danosas à estrutura geral dos sistemas públicos de ensino, continuamos a repetir o lugar-comum de que é preciso desenvolver nas crianças e nos jovens o hábito da leitura. Enquanto se repete essa ladainha, os estudantes que conseguiram chegar no final do segundo grau - topo da escola básica -, que fazem até vestibular (!), continuam não sabendo ler direito um enunciado simples como uma questão de redação. E o que terá sido feito com os que não chegam ao vestibular? Tudo isso porque descolamos os alunos das suas linguagens e os educamos lingüisticamente pela reta de chegada da suposta língua materna e também a partir dos abstratos conteúdos programáticos, ignorando suas experiências e idiossincrasias semântico-culturais.

Por isso, nesse português, essa nossa língua nacional, que muita gente boa acredita que seja só uma nomenclatura - "pura e compreendida por todos" -, que está mais do lado dos que estão ganhando a parada no 
momento, não cabem inúmeras crianças, jovens e adultos brasileiros. Por isso, pra grande maioria, o português mediado pela voz do professor e pela linguagem escrita dos textos, que para alguns poucos é tão natural, não passa de uma língua estrangeira, um português estrangeiro, em terras autenticamente brasileiras. Acho que enquanto não tirarmos as conseqüências metodológicas efetivas disso, continuaremos a acreditar que há mesmo uma realidade lingüística universal e anterior a nós, materializada em gramáticas e dicionários do português. Enquanto a carochinha de que as gramáticas e os dicionários existem antes mesmo de o homem ter aprendido a falar e a escrever estiver povoando o nosso imaginário e enquanto essa ilusão servir de mote para expressar o que somos e deveríamos ser em termos de linguagem, continuaremos a ensinar menos do que podemos - e que Deus proteja os estudantes todos, do pré à universidade!

E por falar em universidade, cabe aqui mais uma pergunta: diante de um problema desses, o que podemos fazer com o profissional de Letras? Como melhorar a qualidade da formação dos nossos alunos nos cursos de graduação para que eles possam estar mais preparados para as realidades lingüístico-culturais com que vão se deparar na sala de aula, na mídia e em outros espaços sociais? Penso que num momento em que até os documentos oficiais, como o PCN, por exemplo, estão ressaltando a necessidade de uma maior atenção sobre as questões da diversidade cultural de regiões, escolas e alunos, baseando-se num ainda prenúncio de discurso acadêmico que pretende ver a prática do homem integrada a sua prática lingüística, quero crer que, no mínimo, precisamos abrir os olhos da moçada e dizer que o mundo, dentro e fora da sala de aula - tão ilusoriamente semelhante -, é mais complexo, diverso e rico do que a nossa vã Lingüística pode supor. Com isso, talvez possamos construir aqui no chão - e um pouco de otimismo não faz mal a ninguém nesses tempos tão difíceis -, sob o olhar fixo dos gramáticos da mídia e de todos aqueles que só conseguem pensar as palavras com cabeça de dicionário, um mapa do país mais real e diferente daquele das aulas de geografia e ensinar melhor um pouco desse português estrangeiro para brasileiros tão diferentes. 


\section{REFERÊNCIAS}

GARCEZ, P. M.; ZILLES, A. M. S. Estrangeirismos - desejos e ameaças. In: FARACO, C. A. (Org.). Estrangeirismos - guerras em torno da língua. São Paulo: Parábola, 2001.

RAMOS, G. Infância. São Paulo: Record, 1981.

Texto recebido em 22 jul. 2002

Texto aprovado em 26 ago. 2002 